\title{
MODULAÇÃO SIMULTÂNEA DA TEMPERATURA E DA VAZÃO DO AR NA ENTRADA DE UM SECADOR EM LEITO FIXO
}

\author{
R. O. DEFENDI ${ }^{1}$, P. R. PARAÍSO ${ }^{1}$, L. M. M. JORGE ${ }^{1 *}$ \\ ${ }^{1}$ Universidade Estadual de Maringá, Departamento de Engenharia Química \\ *e-mail:1mmj@deq.uem.br
}

\begin{abstract}
RESUMO
Este trabalho teve como objetivo o estudo da secagem intermitente de soja em leito fixo com a imposição da modulação simultânea da temperatura e da vazão do ar na entrada do secador. A secagem intermitente é uma operação alternativa que visa melhorar o processo em termos de rendimento, de gasto energético ou de qualidade do material. Na secagem intermitente, as condições do ar na entrada do secador como sua temperatura e vazão variam com o tempo contrariamente à operação convencional, na qual estas condições do ar são mantidas constantes. Neste contexto, realizaram-se experimentos de secagem em operação intermitente e convencional e estes resultados foram comparados em termos de rendimento inerente às porcentagens de água evaporada no final do processo. Os experimentos foram realizados em pares, sendo que para cada operação intermitente uma operação tradicional foi realizada de forma a demandar o mesmo consumo energético, mesmo tempo de secagem, mesma demanda de ar e mesmas condições ambientes. Foi observado que por meio da operação com modulações periódicas da temperatura e da vazão do ar, a porcentagem de água evaporada foi maior que a porcentagem obtida em operação tradicional com 5\% de significância.
\end{abstract}

\section{INTRODUÇÃO}

Contrariamente à operação tradicional, a secagem intermitente trabalha com entradas transientes das condições do ar como sua temperatura e vazão. Este tipo alternativo de secagem foi estudado por um significativo número de pesquisadores (BON e KUDRA, 2007; CHIN e LAW, 2010; CHONG e LAW, 2011; CHUA et al., 2003; DEFENDI et al., 2014; FARKAS et al., 1997; GOLMOHAMMADI et al., 2012; HERRITSCH et al., 2010; HOLOWATY et al., 2012; ITAYA et al., 1999; KOWALSKI e PAWOWSKI, 2010 a,b; LI et al., 1998; MENEGHETTI et al., 2012; OLIVEIRA e ROCHA, 2007; ONG et al., 2012; PUTRANTO et al., 2011; PUTRANTO e CHEN, 2013; SHEI e CHEN, 2002; SMITH e
LANGRISH, 2008; THOMKAPANICH et al., 2007; ZHANG e LITCHFIELD, 1991). Um dos principais objetivos deste tipo de operação é modular as condições do ar de secagem de forma a minimizar o consumo energético, aumentar o rendimento do processo ou reduzir as perdas de qualidade do material (PUTRANTO et al., 2011; PUTRANTO e CHEN, 2012).

Segundo Chua et al. (2003), a secagem intermitente é benéfica para materiais cuja secagem é controlada pela difusão interna de calor e umidade dentro do grão. A maioria dos produtos agrícolas como a soja possui esta característica. Neste contexto, a modulação das condições do ar como temperatura e vazão pode proporcionar ganhos de competitividade, economia e qualidade. 
Outro fato interessante a ser ressaltado é que o processo de secagem pode danificar a qualidade dos produtos (PUTRANTO e CHEN, 2013), especialmente quando se opera em temperaturas muito altas com os materiais termossensíveis. Assim, Chua et al. (2003) ainda acrescentam que esta variação de energia na entrada do secador devida a modulação da temperatura do ar é também benéfica para materiais sensíveis à variação de calor como comidas, ervas, temperos e medicamentos à base de plantas, pois o tempo em contato com ar em temperaturas altas é reduzido.

Em operação intermitente, as condições do ar podem ser moduladas de várias formas, como em perturbações degraus ou no formato senoidal. Além disso, podem ser moduladas várias condições do ar como a temperatura, vazão, pressão e umidade, as quais são propriedades que impactam nas taxas de secagem, na qualidade do material a ser seco e no consumo energético do processo.

Alguns autores observaram que foi possível reduzir o consumo energético com a operação intermitente em comparação com os resultados obtidos em operação convencional, onde as condições do ar foram mantidas em valores constantes na entrada do secador (CHIN e LAW, 2010; HOLOWATY et al., 2012; 2001; THOMKAPANICH et al., 2007; ZHANG e LITCHFIELD, 1991). Outros estudos apontaram que a operação intermitente pode reduzir o tempo efetivo de secagem (CHIN e LAW, 2010; CHONG e LAW, 2011; FARKAS et al., 1997; HERRITSCH et al., 2010; ONG et al., 2012; THOMKAPANICH et al., 2007; ZHANG e LITCHFIELD, 1991; KOWALSKI e SZADZINSKA, 2014) e pode melhorar a qualidade do material seco (BON e KUDRA, 2007; CHIN e LAW, 2010; CHONG e LAW, 2011; FARKAS et al., 1997; KOWALSKI e PAWOWSKI, 2010 a,b; ONG et al., 2012; THOMKAPANICH et al., 2007) em comparação com os resultados obtidos em operação tradicional.

Neste contexto, o objetivo deste trabalho foi estudar a secagem intermitente de grãos de soja (Glycine max) em leito fixo com a imposição da modulação simultânea da temperatura e da vazão do ar na entrada do secador. Objetivou-se realizar experimentos de secagem em operação intermitente e convencional e comparar estes resultados em termos de rendimento inerente às porcentagens de água evaporada no final do processo. Os experimentos foram realizados em pares, sendo que para cada operação intermitente uma operação tradicional foi realizada de forma a demandar o mesmo consumo energético, mesmo tempo de secagem, mesma demanda de ar e mesmas condições ambientes. Um tratamento estatístico foi usado para analisar se houve diferença significativa entre as médias das porcentagens de água evaporada das operações periódicas e convencionais. O método utilizado foi o teste $\mathrm{t}$ pareado descrito por Montgomery e Runger (2003).

\section{MATERIAIS E MÉTODOS}

\subsection{Materiais}

Os equipamentos e materiais utilizados foram um compressor que opera a 7 bar, um aquecedor elétrico com resistência de 7,60 $\Omega$, um regulador de tensão (VARIAC) para controlar a voltagem aplicada no aquecedor, um rotâmetro, um secador de leito fixo isolado com lã de $6 \mathrm{~cm}$ de diâmetro interno e $30 \mathrm{~cm}$ de comprimento, um psicrômetro digital, 17 termopares do tipo $\mathrm{K}$ (precisão de $\pm 2,2{ }^{\circ} \mathrm{C}$ ), um cronômetro, soja do tipo EMBRAPA 48 (diâmetro médio em torno de $6 \mathrm{~mm})$ fornecida pela COCAMAR, uma balança com leitura mínima de 0,01 g, uma balança analítica com leitura mínima de 0,0001 g, um paquímetro digital, bolinhas de isopor (diâmetro de $5 \mathrm{~mm}$ ) e uma estufa que opera a $105^{\circ} \mathrm{C} \pm 2{ }^{\circ} \mathrm{C}$. 
O sistema analisado é análogo ao utilizado por Fregolente et al. (2004). O ar do sistema é fornecido pelo compressor em cuja linha de tubulação há um rotâmetro para quantificar a vazão de ar. $\mathrm{O}$ ar segue para um aquecedor elétrico que possui um dispositivo para regular a voltagem aplicada. Em seguida, o ar percorre o leito do secador, onde há vários termopares situados em diferentes posições. A posição dos termopares no leito está apresentada pela Tabela 1. No topo do secador, termopares anelares com cinco sensores de temperatura foram colocados analogamente ao estudo de Jorge et al. (2003).

Tabela 1 - Posição dos Termopares

\begin{tabular}{cccc}
\hline $\begin{array}{c}\text { Posição } \\
\text { no leito } \\
\text { (cm) }\end{array}$ & $\begin{array}{c}\text { Número de } \\
\text { Termopares }\end{array}$ & $\begin{array}{c}\text { Posição } \\
\text { no leito } \\
\text { (cm) }\end{array}$ & $\begin{array}{c}\text { Número de } \\
\text { Termopares }\end{array}$ \\
\hline 0,0 & 3 & 20,3 & 1 \\
5,3 & 1 & 23,3 & 1 \\
8,3 & 1 & 26,3 & 1 \\
11,3 & 1 & 29,3 & 1 \\
14,3 & 1 & 30,0 & 5 \\
17,3 & 1 & & \\
\hline
\end{tabular}

\subsection{Procedimento Experimental}

Primeiramente, ajustou-se a vazão do ar e sua temperatura inicial ligando a resistência na primeira posição desejada aguardando-se até que o ar atinja temperatura constante. A temperatura, a umidade absoluta e a umidade realtiva foram medidas tanto para o ar de secagem quanto para o ar ambiente. Em sequência, preencheu-se a base do leito com bolas de isopor que serviram como suporte ao leito de soja e ajudaram a uniformizar o fluxo de ar para evitar caminhos preferenciais. Além disso, o isopor apresenta alta inércia térmica e baixa absorção de umidade. Os trinta centímetros do leito do secador isolado foram preenchidos apenas com soja, cuja massa foi quantificada. Quatro amostras da soja utilizada foram levadas em estufa a 105 ${ }^{\circ} \mathrm{C} \pm 2{ }^{\circ} \mathrm{C}$ durante 24 horas a fim de se determinar o teor de umidade inicial. A umidade inicial média das amostras foi em torno de $20 \%$ em base seca

Com o leito preenchido, a linha do ar de secagem foi plugada na entrada do secador e secou-se o material durante 1 hora. As temperaturas em cada termopar foram medidas ao longo do processo. O psicrômetro foi acoplado na saída do secador para medir a umidade absoluta e a temperatura do ar que deixa o leito. No final do processo, a massa de soja seca foi quantificada e quatro amostras foram levadas em estufa a $105{ }^{\circ} \mathrm{C} \pm 2{ }^{\circ} \mathrm{C}$ durante 24 horas para se determinar o teor médio de umidade final da soja.

Foram realizados dois tipos diferentes de experimentos, sendo um com modulação da vazão do ar juntamente com fornecimento de calor ao ar a uma taxa de fluxo constante e o outro consistiu na modulação simultânea do calor fornecido ao ar e da sua vazão. No primeiro caso a voltagem aplicada ao aquecedor do ar permaneceu num valor constante durante todo o experimento de forma que a modulação na temperatura do ar ocorreu devido às variações na vazão do ar ao passar pelas resistências do aquecedor. A Tabela 2 apresenta como a vazão do ar foi modulada para este caso. No segundo caso, tanto a voltagem aplicada quanto a vazão do ar foram alternadas em intervalos iguais conforme a Tabela 3. Neste caso, houve modulação simultânea da taxa de fluxo de calor fornecida ao ar e da vazão. Em ambos os casos, houve variação da velocidade e da temperatura do ar na entrada do secador.

Para cada experimento de secagem periódica com modulação das condições do ar na entrada do secador, um experimento de secagem convencional (vazão e temperatura do ar constante durante todo o processo na entrada do secador) foi conduzido no mesmo dia para evitar interferências inerentes às condições climáticas nas análises comparativas entre os rendimentos de ambas as operações. 
Tabela 2 - Modulação da Vazão com Aquecimento do Ar em Taxa de Fluxo Constante

\begin{tabular}{ccc}
$\begin{array}{c}\text { Primeira / } \\
\text { Segunda } \\
\text { Posição da } \\
\text { Vazão (L/min) }\end{array}$ & $\begin{array}{c}\text { Intervalo } \\
\text { Entre Cada } \\
\text { Perturbação } \\
(\text { min) }\end{array}$ & $\begin{array}{c}\text { Posição do } \\
\text { Regulador } \\
\text { da Voltagem } \\
(\%)\end{array}$ \\
\hline A) $200 / 40$ & 10 & 17 \\
B) $40 / 200$ & 10 & 17 \\
C) $200 / 40$ & 30 & 17 \\
D) $200 / 40$ & 5 & 17 \\
E) $170 / 70$ & 10 & 17 \\
F) $140 / 100$ & 10 & 17 \\
\hline
\end{tabular}

Tabela 3 - Modulação Simultânea da Vazão e da Taxa de Fluxo de Calor do Aquecimento do Ar

\begin{tabular}{ccc}
\hline $\begin{array}{c}\text { Primeira / } \\
\text { Segunda } \\
\text { Posição da } \\
\text { Vazão (L/min) }\end{array}$ & $\begin{array}{c}\text { Intervalo } \\
\text { Entre Cada } \\
\text { Perturbação } \\
(\text { min) }\end{array}$ & $\begin{array}{c}\text { Primeira / } \\
\text { Segunda } \\
\text { Posição do } \\
\text { Regulador } \\
\text { da Voltagem } \\
(\%)\end{array}$ \\
\hline G) $200 / 40$ & 10 & $0 / 20$ \\
H) $40 / 200$ & 10 & $0 / 20$ \\
I) $40 / 200$ & 10 & $20 / 0$ \\
J) $200 / 40$ & 10 & $20 / 0$ \\
\hline
\end{tabular}

As operações convencionais foram realizadas de forma a consumir o mesmo gasto energético inerente à energia que entra no aquecedor, o mesmo tempo de secagem (uma hora) e a mesma demanda de ar (trabalhou-se com a vazão média da operação periódica, cujo valor foi de $120 \mathrm{~L} / \mathrm{min}$ ) em relação às quantidades obtidas de suas respectivas secagens periódicas. Os experimentos foram realizados em duplicata e em sequência randômica. A quantidade de energia consumida durante a operação periódica foi calculada por meio da seguinte expressão:

$$
E_{P}=\dot{m}_{a r} \int c p_{a r} \cdot T a_{P} \cdot d t
$$

Em que $\mathrm{Ta}_{\mathrm{P}}$ é a temperatura do ar de alimentação da operação periódica, $\dot{\mathrm{m}}_{\mathrm{ar}}$ é a vazão mássica do ar, $\mathrm{cp}_{\mathrm{ar}}$ é o calor específico do ar e t é o tempo. Este consumo energético avalia a quantidade de energia que $\mathrm{o}$ ar fornece na entrada do secador para que a secagem ocorra. Uma vez que o leito é adiabático, essa quantidade foi a energia consumido pelo processo de secagem. Neste cálculo de consumo energético, não se levou em conta a forma que o ar foi aquecido, que neste caso foi por meio de resistências elétricas. O intuito deste estudo é avaliar se com o mesmo fornecimento de energia na entrada do secador é possível aumentar o rendimento do processo com uso da modulação das condições do ar. Para processos industriais, é interessante integrar este estudo de rendimento com os custos inerentes ao processo de aquecimento do ar.

Como a temperatura do ar é constante em operação convencional, a energia consumida para a operação convencional é dada por:

$$
E_{C}=\dot{m}_{a r} c p_{a r} \cdot T a_{C} \cdot t
$$

Em que $\mathrm{Ta}_{\mathrm{C}}$ é a temperatura do ar de alimentação da operação convencional. Para garantir o mesmo consumo energético em ambas as operações, a temperatura do ar na entrada do secador para a operação convencional foi determinada calculando uma média para a temperatura na entrada do secador de sua respectiva operação periódica. Assim, a energia fornecida na entrada do secador foi a mesma em ambas as operações conduzidas no mesmo dia (a energia calculada pelas Equações 1 e 2 respectivamente para a operação intermitente e convencional foi a mesma ao se determinar $\mathrm{Ta}_{\mathrm{C}}$ por meio da Equação 3). Essa temperatura média foi calculada com os dados experimentais integrando numericamente a seguinte equação:

$$
T a_{C}=\frac{\int T a_{P} \cdot d t}{\int d t}
$$




\section{RESULTADOS}

\subsection{Modulação da Vazão com Aquecimento do Ar em Taxa de Fluxo Constante}

Dos resultados obtidos, observou-se que as taxas de secagem foram maiores em operação intermitente em comparação a sua respectiva operação convencional, pois a porcentagem de água evaporada foi superior em operação periódica como demonstra a Tabela 4. A porcentagem de água evaporada foi calculada pela quantidade de água evaporada (diferença entre a massa inicial e final do leito de soja) dividida pela quantidade de água inicial (estimada pelo teor de umidade inicial da soja)

A Figura 1 apresenta o gráfico de temperatura na entrada e na saída do secador referentes ao experimento A da Tabela 2, cuja modulação da vazão foi feita entre 200 e 40 $\mathrm{L} / \mathrm{min}$ em intervalos de 10 minutos com o aquecedor ligado na posição do regulador da voltagem de $17 \%$. Observa-se deste gráfico que a temperatura do ar oscila tanto na entrada quanto na saída do secador. Estas oscilações beneficiaram a secagem uma vez que potenciaram os transportes de massa e de energia entre o grão e o ar aumentando assim as taxas de secagem. Estes dados ainda indicam que as taxas de secagem não são linearmente proporcionais à temperatura, pois o aumento da temperatura compensou as baixas taxas de secagem em baixos valores de temperatura em comparação com as taxas obtidas na operação convencional com temperatura constante no valor médio da temperatura de operação intermitente. Vale ressaltar que as análises de taxa de secagem estão baseadas nas porcentagens de água evapora, de forma que quanto maior as porcentagens de água evaporada, maiores são consequentemente as taxas de secagem.

O impacto da amplitude da modulação da vazão do ar pode ser observado na Figura 2 que apresenta gráfico de umidade do ar na saída do secador para diferentes amplitudes de modulação da vazão.

Verificou-se que quanto menor a vazão do ar, mais altos são os níveis de umidade na saída do secador. Estes resultados não indicam quanto maior os níveis de umidade do ar na saída do secador maiores são as taxas de secagem, pois as vazões do ar alternaram. Quanto maior a vazão do ar, menos tempo este fica dentro do secador e menor é a quantidade de água por massa de ar que é transportada com o tempo. Quanto menor a vazão, maiores são as possibilidades de o ar saturar e quanto mais saturado o ar maiores são as pressões parciais do vapor de água no ar. Estes fatos dificultam o transporte de massa de água do grão para o ar, o que impacta numa redução das taxas de secagem.

Tabela 4 - Porcentagem de água evaporada

\begin{tabular}{ccc}
\hline \multicolumn{3}{c}{ Porcentagem de Água Evaporada (\%) } \\
\hline $\begin{array}{c}\text { Experimento } \\
\text { (Tabela 2) }\end{array}$ & $\begin{array}{c}\text { Operação } \\
\text { Periódica }\end{array}$ & $\begin{array}{c}\text { Operação } \\
\text { Convencional }\end{array}$ \\
\hline A & 29,8 & 25,3 \\
A & 27,3 & 22,9 \\
B & 28,8 & 25,1 \\
B & 29,9 & 25,1 \\
C & 35,6 & 28,5 \\
C & 31,5 & 26,6 \\
D & 34,5 & 28,1 \\
D & 31,4 & 25,9 \\
E & 35,6 & 28,9 \\
E & 31,3 & 26,9 \\
F & 35,9 & 30,6 \\
F & 31,4 & 26,0 \\
\hline
\end{tabular}

Figura 1 - Temperatura na entrada e saída para o experimento $\mathrm{A}$

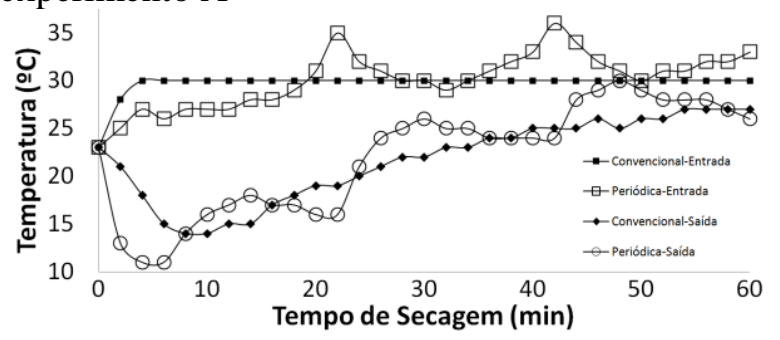


Figura 2 - Umidade do Ar na Saída do Secador para Diferentes Amplitudes

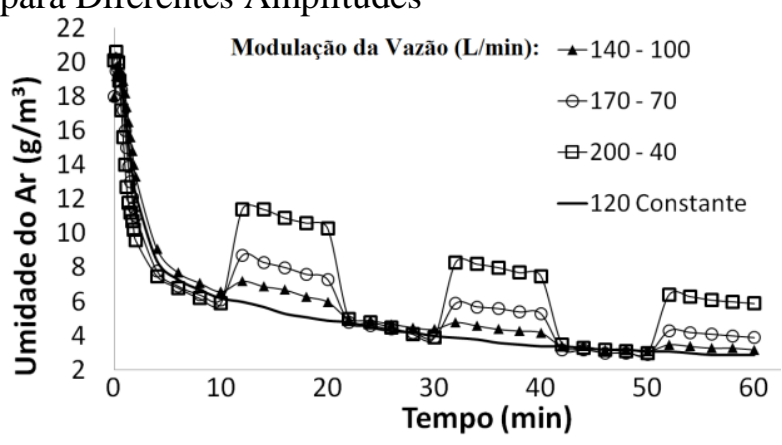

$\mathrm{O}$ teste $\mathrm{t}$ pareado descrito por Montgomery e Runger (2003) foi utilizado para ver se houve diferença significativa entre as médias das porcentagens de água evaporada das operações periódicas e convencionais com o auxílio do Software R. Este método é ideal para amostras de pequenos tamanhos com variâncias desconhecidas e para observação de duas populações de interesse quando os dados coletados são feitos em pares e em condições homogêneas.

Para se utilizar o teste pareado t, é necessário que as amostras tenham distribuição normal e que as amostras tenham variâncias homogêneas. $\mathrm{O}$ teste de normalidade de Shapiro-Wilk apontou com $5 \%$ de significância que os dados referentes às porcentagens de água evaporada apresentam distribuição normal com os valores $\mathrm{p}$ de 0,2294 e de 0,9465 respectivamente para a operação periódica e convencional. O teste pela função var.test para verificar a igualdade entre as variâncias apontou com o valor $\mathrm{p}$ de 0,3081 que as variâncias são iguais com 5\% de significância.

Além disso, é necessário que os dados sejam coletados em pares e em condições homogêneas. Para cada operação periódica, foi realizado um experimento em operação convencional conduzido no mesmo dia garantindo assim as mesmas condições climáticas. Além disso, ambas as operações foram conduzidas com a mesma amostra de soja (garantindo também a mesma umidade inicial). Assim, os experimentos foram realizados em condições homogêneas e coletados aos pares.

$\mathrm{O}$ teste estatístico pareado $\mathrm{t}$ foi aplicado nas diferenças entre as porcentagens de água evaporada da operação periódica e convencional e este apontou num nível de confiança de $95 \%$ que as operações periódicas e convencionais apresentam diferença significativa entre suas médias de porcentagem de água evaporada em condições de mesmo tempo de secagem, mesmo consumo energético e mesma demanda de ar. O valor $\mathrm{p}$ obtido foi de $1,991.10^{-09}$.

Este resultado indica que houve melhora significativa no desempenho do secador com a operação periódica, pois as taxas de secagem foram significativamente superiores. A Figura 3 apresenta o diagrama de caixa para as porcentagens de água evaporada, onde é possível observar também que há diferença entre as médias das operações periódica e convencional.

Figura 3 - Diagrama de Caixa para a Porcentagem de Água Evaporada

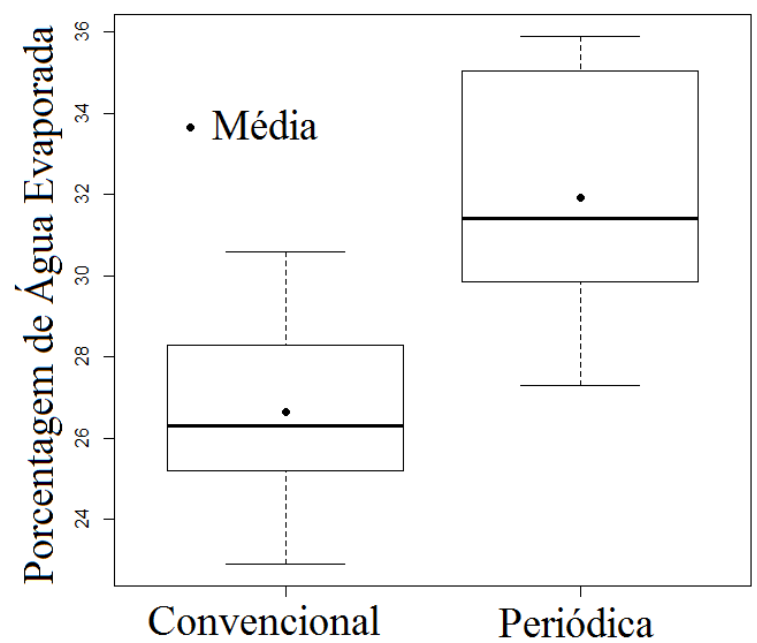

3.2 Modulação Simultânea da Taxa de
Fluxo de Calor do Aquecimento do Ar e da
Vazão
Os resultados obtidos para os experimentos com as modulações simultâneas 
da vazão do ar e da taxa de fluxo de calor cedida ao ar pelo aquecedor apontaram que as porcentagens de água evaporada no processo também foram maiores em operação periódica como mostra a Tabela 5. As oscilações da velocidade e da temperatura do ar na entrada do secador novamente potencializaram os transportes de massa e de energia envolvidos no processo, melhorando as taxas de secagem. A temperatura tem um comportamento específico de acordo com o tipo de modulação, como mostra as Figuras 4, 5, 6 e 7 respectivamente os gráficos de temperatura para os experimentos $\mathrm{G}$ (inicia com velocidade alta e temperatura baixa), $\mathrm{H}$ (inicia com velocidade e temperatura baixa), I (inicia com velocidade baixa e temperatura alta) e $\mathbf{J}$ (inicia com velocidade e temperatura alta).

Observou-se que as oscilações na temperatura são maiores para os casos dos experimentos $\mathrm{G}$ e I, onde as taxas de fluxo de calor altas estão juntas às velocidades baixas. Para estes casos, a temperatura na entrada do ar resfria e esquenta rapidamente, tendo variações de $10{ }^{\circ} \mathrm{C}$. Temperaturas altas com velocidades altas (casos $\mathrm{H}$ e J) não permitem que $\mathrm{o}$ ar esquente e esfrie muito. É interessante ter altas variações na temperatura do ar como visto anteriormente, pois isto proporciona um aumento nas taxas de secagem. Contudo, constatou-se que todos os tipos de modulações favoreceram a secagem periódica aumentando a porcentagem de água evaporada.

Quanto à umidade na saída do secador, constatou-se que a velocidade do ar é a propriedade que mais impacta em seus valores, pois independente da temperatura do ar, os níveis de umidade foram mais altos em baixas velocidades. Este fato não indica necessariamente que as taxas de secagem foram maiores, visto que o tempo de residência do ar dentro do leito é menor do que o tempo de casos em velocidades altas. As Figuras 8, 9, 10 e 11 apresentam os gráficos de umidade do ar na saída do secador para os experimentos $\mathrm{G}, \quad \mathrm{H}, \quad \mathrm{I} \quad \mathrm{e} \quad \mathrm{J}$ respectivamente.

Tabela 5 - Porcentagem de água evaporada

\begin{tabular}{ccc}
\hline \multicolumn{3}{c}{ Porcentagem de Água Evaporada (\%) } \\
\hline $\begin{array}{c}\text { Experimento } \\
\text { (Tabela 3) }\end{array}$ & $\begin{array}{c}\text { Operação } \\
\text { Periódica }\end{array}$ & $\begin{array}{c}\text { Operação } \\
\text { Convencional }\end{array}$ \\
\hline G & 29,1 & 23,9 \\
G & 29,1 & 24,2 \\
H & 29,5 & 23,9 \\
H & 24,8 & 21,5 \\
I & 31,3 & 27,0 \\
I & 28,9 & 25,2 \\
J & 33,2 & 27,2 \\
J & 32,0 & 25,6 \\
\hline
\end{tabular}

Figura 4 - Gráfico de Temperatura do Caso G

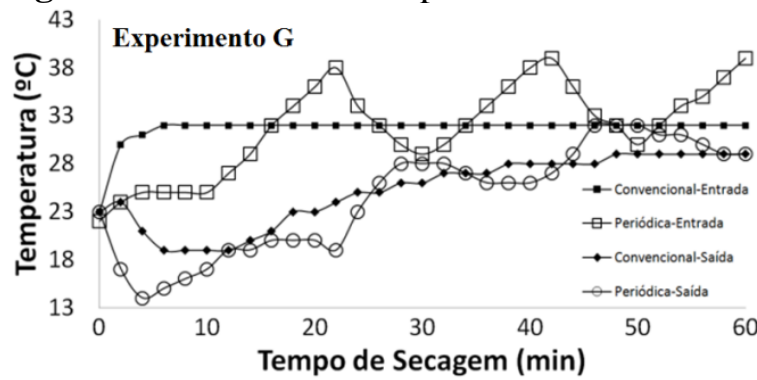

Figura 5 - Gráfico de Temperatura do Caso $\mathrm{H}$

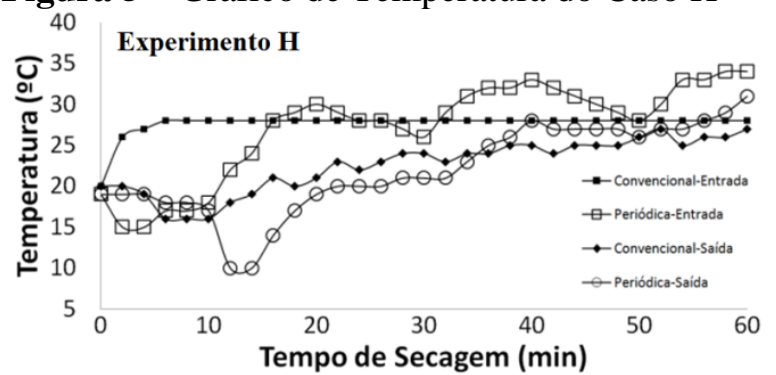

Figura 6 - Gráfico de Temperatura do Caso I

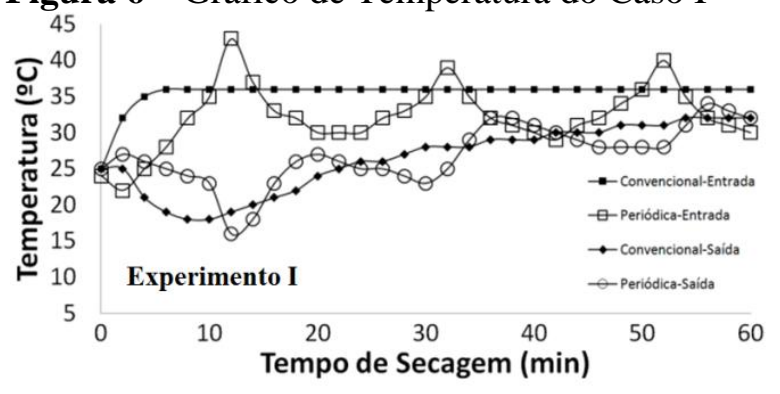


Figura 7 - Gráfico de Temperatura do Caso J

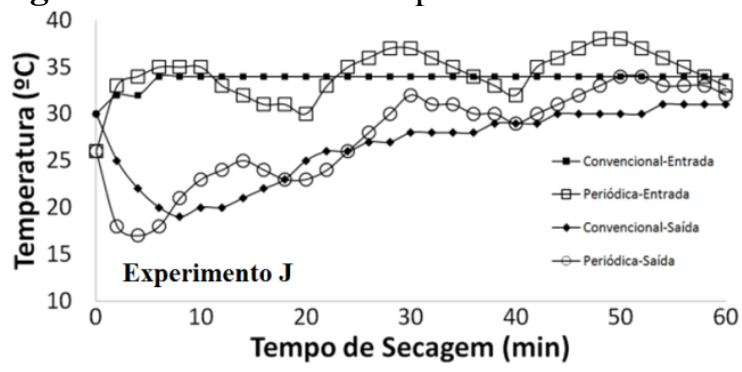

Figura 8 - Gráfico de Umidade do Caso G

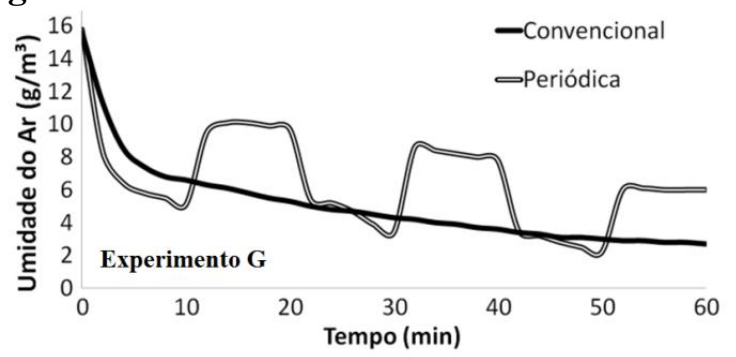

Figura 9 - Gráfico de Umidade do Caso H

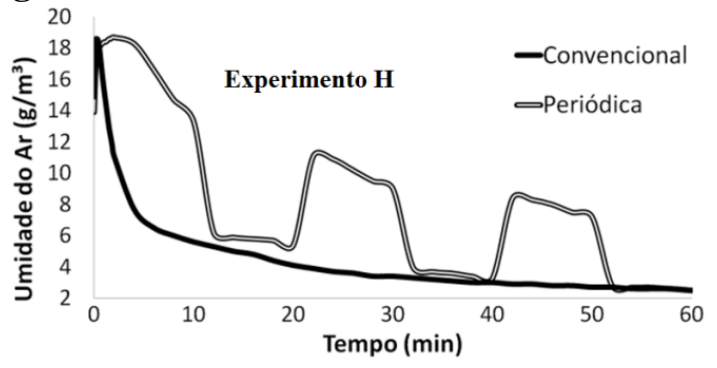

$\underset{27}{\text { Figura } 10}$ - Gráfico de Umidade do Caso I

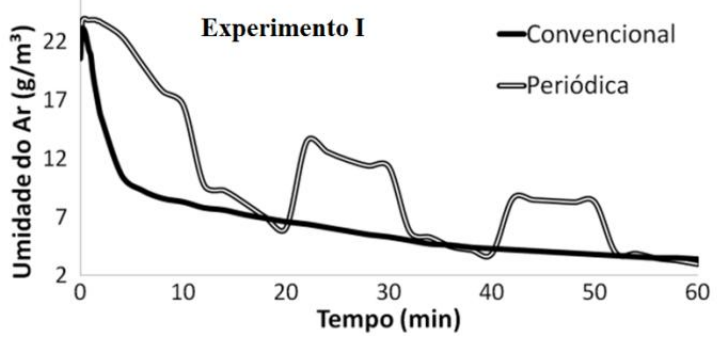

Figura 11 - Gráfico de Umidade do Caso J

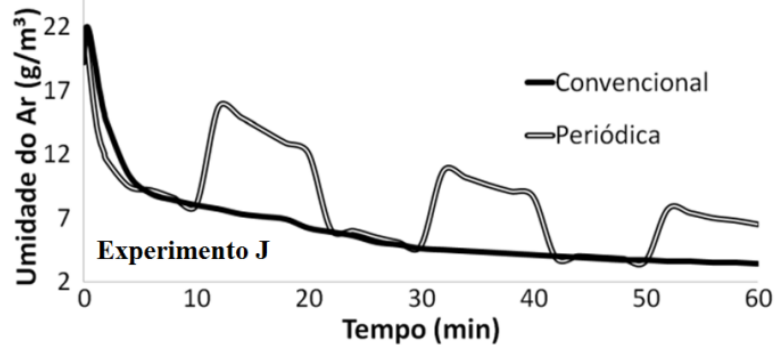

Os testes estatísticos também indicaram melhora no desempenho do secador em operação periódica, pois as quantidades de água evaporada foram significativamente maiores em comparação as quantidades obtidas em operação convencional para casos em que ambas as operações consumiram o mesmo gasto energético, tiveram o mesmo tempo de secagem e demandaram a mesma quantidade de ar. O teste de normalidade de Shapiro-Wilk apontou com o valor $\mathrm{p}$ de 0,4323 para os dados de operação periódica e de 0,6396 para os dados de operação convencional que os dados seguem distribuição normal com 5\% de significância. $\mathrm{O}$ teste de igualdade entre variâncias apontou num nível de $95 \%$ de confiança que as variâncias são iguais. $O$ teste pareado $t$ indicou com $5 \%$ de significância que há diferença significativa entre as médias das porcentagens de água evaporada entre as operações periódica e convencional (valor $\mathrm{p}$ de $4,269.10^{-06}$ ).

A Figura 12 mostra o diagrama de caixa para a distribuição das porcentagens de água evaporada em cada operação. Neste gráfico, nota-se que os níveis percentuais são mais altos para a operação periódica. Além disso, toda faixa de distribuição dos níveis percentuais de água evaporada na operação periódica está em regiões superiores à faixa da operação convencional.

Figura 12 - Diagrama de Caixa para a Porcentagem de Água Evaporada

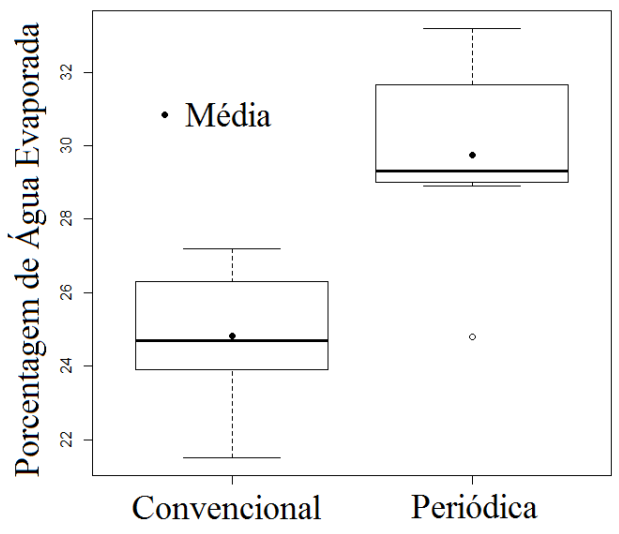




\section{CONCLUSÃO}

Dos resultados obtidos neste trabalho, observou-se que a operação intermitente com modulação simultânea da temperatura e velocidade do ar apresentou ser mais vantajosa que a operação convencional em termos de rendimento referente às taxas de secagem. Testes estatísticos apontaram que as porcentagens de água evaporada em operação periódica foram maiores que as porcentagens obtidas em operação convencional para casos em que ambas as operações foram conduzidas com o mesmo consumo energético, mesmo tempo de secagem, mesma demanda de ar e mesmas condições climáticas. Além disso, observou-se que a propriedade que mais influenciou na umidade do ar na saída do secador foi sua velocidade, sendo que os maiores valores de umidade foram obtidos nas menores vazões.

\section{REFERÊNCIAS}

BON, J.; KUDRA, T. Enthalpy-Driven Optimization of Intermittent Drying. Drying Technology v. 25, n. 4, p. 523-532, 2007

CHIN, S. K.; LAW, C. L. Product Quality and Drying Characteristics of Intermittent Heat Pump Drying of Ganoderma tsugae Murrill. Drying Technology, v. 28, p. 14571465, 2010.

CHONG, C. H.; LAW, C. L. Application of Intermittent Drying of Cyclic Temperature and Step-Up Temperature in Enhancing Textural Attributes of Dehydrated Manilkara zapota. Drying Technology, v. 29, n. 2, p. 245-252, 2011.

CHUA, K. J.; MUJUMDAR, A. S.; CHOU, S. K. Intermittent drying of bioproducts - an overview. Bioresource Technology, v. 90, p. 285-295, 2003.
DEFENDI, R. O; SILVA, R. O.; SILVA, G. E. C.; PARAÍSO, P. R.; JORGE, L. M. M. Simulation and analysis of periodic and conventional drying of soybeans in fixed bed. Artigo Publicado nos anais do 19th International Drying Symposium. 2014.

FARKAS, I.; RENDIK, Z. Intermittent thin layer corn drying. Drying Technology, v. 15, n. 6-8, p. 1951-1960, 1997.

FREGOLENTE, L. V.; SANTOS, O. A. A.; JORGE, L. M. M. Estimativa das Propriedades Térmicas Efetivas de Grãos em um Secador de Leito Fixo. Ciência e Tecnologia de Alimentos, v. 24, n. 2, p. 270276, 2004.

GOLMOHAMMADI, M.; RAJABIHAMANE, M.; HASHEMI, S. J. Optimization of Drying-Tempering Periods in a Paddy Rice Dryer. Drying Technology, v. 30, n. 1, p. 106-113, 2012.

HERRITSCH, A.; DRONFIELD, J.; NIJDAM, J. J. Intermittent and Continuous Drying of Red Beech Timber From the Green Condition. Drying Technology, v. 28, p. 269277, 2010.

HOLOWATY, S. A.; RAMALLO, L. A.; SCHMALKO, M. E. Intermittent drying simulation in deep bed dryer of yerba maté. Journal of Food Engineering, v. 111, p. 110-114, 2012.

ITAYA, Y.; MORI, S.; HASATANI, M. Effect of intermittent heating on dryinginduced strain-stress of molded clay. Drying Technology, v. 17, n. 7-8, 1261-1271, 1999.

JORGE, L. M. M.; OLIVEIRA, G. P.; JORGE, R. M. M.; GIUDICI, R. Time constants determination and analysis for a ring-shaped temperature sensor in fixed bed. 
Acta Scientiarum. Technology, v. 25, n. 1, p. 9-15, 2003.

KOWALSKI, S. J.; PAWOWSKI, A. Drying of Wet Materials in Intermittent Conditions. Drying Technology, v. 28, n. 5, p. 636-643, 2010a.

KOWALSKI, S. J.; PAWOWSKI, A. Modeling of Kinetics in Stationary and Intermittent Drying. Drying Technology, v. 28, n. 8, p. 1023-1031, 2010 b.

LI, Y.B.; CAO, C.W.; YU, Q.L.; ZHONG, Q.X. Study of Rough Rice Fissuring During Intermittent Drying. Drying Technology, v. 17, n. 9, p. 1779-1793, 1998.

MENEGHETTI, V. L.; AOSANI, E.; DA ROCHA, J. C.; DE OLIVEIRA, M.; ELIAS, M. C.; POHNDORF, R. S. Mathematical models for intermittent drying of rice. Revista Brasileira de Engenharia Agrícola e Ambiental, v. 16, n. 10, p. 1115-1120, 2012.

MONTGOMERY, D. C.; RUNGER, G. C. Applied Statistics and Probability for Engineers; John Wiley \& Sons, Inc: United States of America, 2003.

OLIVEIRA, C.A.; ROCHA, S.C.S. Intermittent Drying of Beans in a Spouted Bed. Brazilian Journal of Chemical Engineering, v. 24, n. 4, p. 571-585, 2007.

ONG, S. P.; LAW, C. L.; HII, C. L. Optimization of Heat Pump-Assisted Intermittent. Drying Technology, v. 30, p. 1676-1687, 2012.

PUTRANTO, A.; XIAO, Z.; CHEN, X. D.; WEBLEY, P. A. Intermittent drying of mango tissues: implementation of the reaction engineering approach. Industrial \& Engineering Chemistry Research, v. 50, p. 1089-1098, 2011.
PUTRANTO, A.; CHEN, X. D. Multiphase modeling of intermittent drying using the spatial reaction engineering approach (SREA). Chemical Engineering and Processing: Process Intensification, v. 70, p. 169-183, 2013.

SHEI, H.J.; CHEN, Y.L. Computer simulation on intermittent drying of rough rice. Drying Technology, v. 20, n. 3, p. 615636, 2002.

SILVA, J. de S; BERBERT, P. A.; AFONSO, A. D. L.; RUFATO, S. Qualidade dos Grãos. Secagem e Armazenagem de Produtos Agrícolas. Editora Aprenda Fácil. Segunda Edição. Viçosa, MG. 2008. p. 63 - 104.

SMITH, S.A.; LANGRISH, T.A.G. Multicomponent Solid Modeling of Continuous and Intermittent Drying of Pinus radiata Sapwood Below the Fiber Saturation Point. Drying Technology, v. 26, p. 844-854, 2008 .

THOMKAPANICH, O.; SUVARNAKUTA, P.; DEVAHASTIN, S. Study of Intermittent Low-Pressure Superheated Steam and Vacuum Drying of Heat-Sensitive Material. Drying Technology, v. 25, p. 205-223, 2007.

ZHANG, Q.; LITCHFIELD J.B. An optimization of intermittent corn drying in a laboratory scale thin layer dryer. Drying Technology, v. 9, n. 2, p. 383-395, 1991.

\section{AGRADECIMENTOS}

O presente trabalho foi realizado com o apoio do Conselho Nacional de Desenvolvimento Científico e Tecnológico CNPq - Brasil e com o apoio da COCAMAR por ter disponibilizado soja Embrapa 48. 